\title{
cOM PAULO BOMFIM
}

Príncipe dos poetas brasileiros, título que herdou de Guilherme de Almeida e de Menotti Del Picchia, Paulo Bomfim é também o poeta de São Paulo.

Paulo Lébeis Bomfim nasceu no dia 30 de setembro de 1926 em São Paulo, cidade na qual o bonde era o principal meio de transporte, com boa parte das ruas iluminadas por lampião de gás. Viveu bem no Centro, na esquina das ruas Rego Freitas com Epitácio Pessoa.

Suas raízes paulistanas são muito profundas. $\mathrm{Na}$ Revolução de 32, do alto de sua casa, podia ver os aviões vermelhos da ditadura Vargas bombardeando o Campo de Marte.

Nas reuniões em casa de seu avô, em torno das tias Cecília e Magdalena Lébeis, cantoras de música de câmara, conheceu duas gerações de artistas: Coelho Neto, Alberto de Oliveira, Martins Fontes, Mário de Andrade, Guilherme de Almeida, Menotti Del Picchia, Cassiano Ricardo, Tácito de Almeida, Paulo Setúbal.

Iniciou suas atividades jornalísticas em 1945, no Correio Paulistano, indo a seguir para o Diário de São Paulo a convite de Assis Chateaubriand. Produziu e apresentou programas no rádio e televisão na década de 40 .

Em 1947 iniciou sua trajetória de escritor. Seu livro de estréia foi Antônio Triste, com prefácio de Guilherme de Almeida e ilustrações de Tarsila do Amaral. A obra foi premiada em 1948 pela Academia Brasileira de Letras com o "Prêmio Olavo Bilac". Fizeram parte da comissão julgadora, Manuel Bandeira, Olegário Mariano e Luiz Edmundo. Seguiram-se dezenas de publicações. Enveredou-se pelos caminhos do soneto inglês, das cantigas - que foram musicadas por Camargo Guarnieri e outros - lançando-se a profundas vivências ancestrais em Armorial, seu livro preferido. Suas obras foram traduzidas para o alemão, o francês, o inglês, o italiano e o castelhano.

Em 23 de maio de 1963 entrou para a Aca- demia Paulista de Letras onde ocupa a cadeira de número 35. Em 1981 foi eleito Intelectual do Ano pela União Brasileira de Escritores, conquistando o "Troféu Juca Pato". Em 1991 recebeu o título de "Príncipe dos Poetas Brasileiros", outorgado pela Revista Brasília e o prêmio "Obrigado São Paulo", da TV Manchete.

Suas últimas publicações foram a edição bilíngüe de Navegante pela Amaral Gurgel, e Cancioneiro editado e ilustrado por Adriana Florence, obras que comemoram os 60 anos de lançamento de Antônio Triste.

Decano da Academia Paulista de Letras e Assessor da Presidência do Tribunal de Justiça do Estado de São Paulo, Paulo Bomfim falou a Augusto Guzzo Revista Acadêmica sobre educação, bandeirismo, juventude e, claro...poesia.

A.G.R.A. O senhor foi educado em uma família que vivia a efervescência cultural dos anos 20 e 30. Acostumou-se com a leitura, a música e as artes em reuniões dentro da casa de sua avó. A educação formal oferecida pelas escolas era rígida e os sistemas de avaliação menos permissivos. De lá para cá a educação brasileira passou por diversas reformulações. Como o senhor analisa o atual estágio da educação brasileira?

Paulo Bomfim - Com certa perplexidade. As teorias nem sempre expressam a linguagem da realidade. Há muitos modismos que, em certos casos, não rimam com a realidade. Existe contradição entre o discurso e a ação.

A.G.R.A. O escritor, também membro da Academia Paulista de Letras, Gabriel Chalita, diz que "O poeta é, assim, um educador, e ao educador podemos chamar o poeta da aprendizagem". O senhor vê esta vocação, quase um sacerdócio, quando se trata de educação nos dias de hoje?

Paulo Bomfim - Enxergo esta vocação nos professores que exerceram grande influência na 
minha vida: Antonio Soares Amora, Heraldo Barbuy, Colombo de Almeida, Filomena Tureli, Elisa Camargo - que me ensinou a ler. Aproveito, inclusive, para fazer um tributo a estas pessoas especiais. Sou o que sou em parte à formação que me deram.

Costumo afirmar que vivemos a mecanização dos homens e a espiritualização das máquinas. As exigências do mundo moderno obrigam o professor a correr, lecionar em vários locais e isso acaba se refletindo na falta de convivência entre aluno e professor. Para que esta situação se revertesse, o professor precisaria ser melhor remunerado. Creio firmemente que professor, médico e magistrado deveriam ser vocações e não profissóes. $\mathrm{O}$ professor deve manter sempre que possível a empatia com o aluno. Sem esta chama acesa tudo perde o sentido.

A.G.R.A. Conforme frase atribuída ao filósofo Immanuel Kant, o "estudante não deve aprender pensamentos, deve aprender a pensar”... O estudante brasileiro, na sua concepção, está sendo preparado para pensar?

Paulo Bomfim - Todo estudante deveria aprender a se conhecer melhor para que não se transforme numa colcha de retalhos alheios cobrindo o frio de existir.

A.G.R.A. Segundo relatório da Unesco, ainda há no Brasil 800 mil jovens analfabetos. $\mathrm{O}$ brasileiro está suficientemente consciente de que a educação é um direito ou ainda a encara como um favor do Estado?

Paulo Bomfim - A educação é o mais sagrado dos direitos.

A.G.R.A. Apesar do alarmante número de analfabetos, não há dúvida de que houve uma democratização do acesso à educação, inclusive à educação superior. Isso pode ser considerado um salto de qualidade, ou estamos formando um grande contingente de profissionais diplomados que podem não encontrar eco no mercado de trabalho?

Paulo Bomfim - O mercado de trabalho torna-se cada vez mais exigente. O caminho da especialização, no entanto, não deve desviar o estudante de uma visão panorâmica da realidade e da cultura.

A.G.R.A. O senhor se considera um inquieto, tanto que entrou na São Francisco, saiu para cursar História, voltou às Arcadas e abandonou o curso pelo jornalismo. Viveu, e vive, com entusiasmo, sem temer os desafios, fazendo sempre o que o realiza. Como o senhor vê a juventude brasileira deste século XXI, sobretudo a que reside em São Paulo? Uma juventude inquieta, como a de seus tempos, ou apática, diante de tantos desafios?

Paulo Bomfim - A juventude está à procura de sua verdade. Falta apenas um grande tema para se viver. Falta uma bandeira, um ideal. Cada um tem que descobrir o seu. Perguntar-se sempre quem sou eu, que rumo meus passos vão tomar e devem tomar.

O eu pessoal está se tornando o eu tribal. Os jovens reagem em grupo. É preciso buscar uma identidade própria.

A.G.R.A. Falamos de uma juventude oriunda de muitas partes do país e de muitos nichos sócio-culturais. Como criar uma identidade paulistana para esses jovens? Como os escritores, jornalistas, artistas, poetas podem contribuir para isso?

Paulo Bomfim - Fazendo com que se conheça melhor glórias e angústias de nosso povo. A árvore que ignora suas raízes não poderá dar bons frutos no futuro.

A.G.R.A. No Brasil, segundo a Associação Nacional de Livrarias, existem cerca de 2700 livrarias, considerando-se apenas estabelecimentos que possuem estoque de, no mínimo, $10 \mathrm{mil}$ títulos, concentrando-se em São Paulo o maior centro livreiro do país. O brasileiro lê pouco mesmo?

Paulo Bomfim - A coisa mais difícil para um autor é ver seu livro admitido nas livrarias. A dificuldade principia em achar uma editora que se digne a ler seu texto. Em seguida vem o problema da distribuição do livro e o silêncio dos noti- 
ciários especializados. A classe $\mathrm{C}$ engolfada em seus problemas econômicos, lê pouco; a classe $B$ namora muito antes de adquirir um livro cujo preço equivale a um dia de trabalho. A classe $\mathrm{A}$ adquire livros da moda que acabam enfeitando suas estantes.

Para um escritor estreante a jornada é difícil. Recordo-me de meu primeiro livro, Antônio Triste, cuja edição foi paga por meu pai. Este primeiro livro custeou o segundo e assim até o quarto livro quando consegui que a Editora Martins começasse a editar minhas obras.

Hoje as livrarias são grandes redes espalhadas pelo país. Em geral, uma rede com 40 lojas compra cerca de 20 exemplares de uma obra e assim o título se dilui. É uma política perversa, por assim dizer. Expor um livro, então!...

Falta a intimidade das antigas livrarias, nas quais o vendedor conhecia seus clientes e as obras que potencialmente poderiam lhe interessar. Hoje é tudo muito frio. Compram-se livros pela embalagem apetitosa e nem sempre o conteúdo corresponde.

Por todas essas dificuldades, respeito o heroísmo do autor brasileiro. Luta incessantemente para publicar, distribuir e expor seu livro e depois vai lutar muitas vezes com a incompreensão do leitor.

A.G.R.A. O senhor tem acompanhado as transformações ocorridas nos últimos anos nos livros didáticos? Como analisa a releitura de fatos históricos que vem sendo apresentada nos livros didáticos? O senhor, que descende do bandeirante Manuel Preto, fundador do bairro paulistano da Freguesia do Ó, por exemplo, como vê a nova abordagem do movimento das bandeiras?

Paulo Bomfim - Não é uma abordagem e sim uma abortagem do bandeirismo. $\mathrm{O}$ bandeirismo deu um corpo âo Brasil e o Império uma alma.

Infelizmente, foi criado no paulista um complexo de culpa em relação ao passado. Criaram um pudor. Os bandeirantes acusados de bandidos, a Revolução de 32, tachada como revolução burguesa. Trinta e dois foi a maior manifestação do povo paulista. Nunca mais veremos algo igual. Outras manifestações como as diretas-já, por exemplo, foram importantes, mas faltou esta coisa sagrada de 32, tão mal compreendida nas escolas superiores. Faço o que posso para manter viva esta memória, mas sou solitário. Fico pensando: em que mãos vou deixar a causa paulista quando eu partir?

A.G.R.A. Deixando a estante dos livros didáticos, vamos falar um pouco sobre os campeões de venda. Hoje, os livros de auto-ajuda tornaram-se os best sellers. Apesar de todo o cientificismo, a alma humana continua sendo o centro do cosmo?

Paulo Bomfim - É o único ponto de referência de que dispomos para interpretar o mistério de existir.

A.G.R.A. Falando, agora, particularmente, do "Príncipe dos Poetas Brasileiros", o "Poeta de São Paulo", título que o senhor considera o mais honroso de todos. Como está sua produção literária. Fale-nos um pouco sobre Navegante.

Paulo Bomfim - O Navegante, edição bilíngüe que está sendo lançada concomitantemente no Brasil e em países hispânicos, é um Colecionador de Minutos renascido e renovado numa visão diferente dos passos do peregrino do êxtase.

A.G.R.A. No Colecionador de Minutos o senhor diz: "Nós passamos uma época da vida colecionando emoções e outra colecionando saudades". O senhor se considera um saudosista?

Paulo Bomfim - Sou um homem de bom gosto. Convivi com gente tão fantástica que me acho no direito de ser exigente.

A.G.R.A. Fale mais sobre seus trabalhos futuros. O senhor está preparando nova publicação?

Paulo Bomfim - A historiadora Ana Luiza Martins está organizando meu próximo livro, Insólita Metrópole, uma visão de São Paulo através de textos, que deverá ser lançado daqui a três meses.

A.G.R.A. E seu agitado cotidiano dividido entre a poesia, o jornalismo, a Academia Paulista de Letras e o Cerimonial do Tribunal de Justiça de São Paulo? 
Paulo Bomfim - Minha poesia deve muito ao agitado cotidiano. Não conseguiria sobreviver sem essa paixão existencial.

A.G.R.A. Recentemente o senhor disse que a poesia é como o petróleo, forma-se no subsolo e jorra quando menos esperamos. Como funciona este processo de criação?

Paulo Bomfim - Exatamente assim, mas devo completar que para que este petróleo não se perca, é preciso ter em mãos o recipiente e este é a forma. Aliás, estamos carecendo de forma. $\mathrm{Na}$ arte, por exemplo. Esta, que deveria ser o alimento para a anemia espiritual que estamos passando, está sofrendo de falta de amor. Há muita piada sendo levada a sério.

A.G.R.A. Há pouco comentávamos a inquietude do jovem Paulo Bomfim. O poeta continua amando a liberdade? O senhor reafirmaria que "sou um rebelde de paletó e gravata, grão que teima em não virar massa, pássaro que persiste no canto dentro da gaiola dos horários"?

Paulo Bomfim - Sim, escrevi certa vez que amo tanto a liberdade que gostaria de ter filhos com ela.

A.G.R.A. O senhor se declara homem de muitas paixões. Nós também acreditamos que nada se faz sem paixão. Como está a paixão no mundo de hoje?

Paulo Bomfim - O amor vai se transformando em contrato de ternura.
A.G.R.A. O senhor diria que as pessoas hoje temem o amor? E acabam nem chegando à ternura?

Paulo Bomfim - Sim, as pessoas temem o amor. Estão tão inseguras que temem qualquer coisa que arranhe as máscaras que elas criaram. Perderam a capacidade da entrega. O amor só vale quando há enriquecimento. A gente entra um e sai outro. E isso vale, inclusive, para a educação que deve ser um ato de amor.

Lembro-me de dona Soledade... Estudei no Colégio Rio Branco junto com Antônio Ermírio de Moraes. Dona Soledade foi nossa professora e acompanhou nossos passos a vida toda. Um dia mandou recado que queria nos ver com urgência. Fomos juntos, chegamos apreensivos pensando estar acontecendo algo com ela. Mas dona Soledade nos surpreendeu dizendo estar muito preocupada com os dois. Com sua ternura nos advertiu: "Os bilhetes que vocês me mandam estão escritos com letra muito feia. Venham uma vez por semana aqui em casa para fazer exercícios de caligrafia".

Essa é a professora que nos amou e esta é a educadora que amamos...

A.G.R.A. Está faltando poesia em nossas vidas?

Paulo Bomfim - Claro que sim. Falta poesia porque falta paixão. $\bigcirc$ poema que deveria ser uma fatia da vida, mineralizou-se num jogo de palavras. 